\title{
ENGAGING FACULTY IN LEADING COLLABORATIVE RESEARCH
}

\author{
Prem S. Paul \\ Vice Chancellor for Research and Dean of Graduate Studies \\ University of Nebraska-Lincoln
}

Summary

The University of Nebraska-Lincoln (UNL) has enjoyed a significant surge in research funding in the last four years. This can be attributed primarily to interdisciplinary collaborations, an infrastructure to support faculty in preparing large multidisciplinary research proposals, seed funding for collaborative research clusters and additional investments in faculty and operational support in targeted areas of strength, with increased expectations for leveraging these resources.

\section{Introduction}

The last decade has seen substantial increases in the federal R\&D budget. This has been especially significant for biomedical research, as the budget for the National Institutes of Health doubled and now is over $\$ 28$ billion. Many academic institutions have benefited from this increase in R\&D investments, including the University of Nebraska-Lincoln, with research expenditures increasing from $\$ 102.7$ million to $\$ 184.7$ million, or 80 percent, in the past decade. Numerous factors have played an important role in this increase, the most significant being the development at the University of Nebraska-Lincoln of Vision 2020: The Future Role of Research and Graduate Education at UNL, and the faculty and administration buy-in to this vision. Although we have a long way to go toward our goal, this institutional emphasis on uncompromising excellence and quality has resulted in record research funding in FY2004 of $\$ 91.5$ million for the University of Nebraska-Lincoln and $\$ 162$ million for all four campuses of the University of Nebraska. For UNL, research funding has increased $86 \%$ in the last four years and $\mathrm{NIH}$ funding has increased $297 \%$ in the same period. Much of this increase has come from large federal grants based on collaborations across departments and colleges. In 2000, UNL held a handful of large multimillion dollar grants; today we have numerous collaborative multimillion dollar grants and centers funded through competitive grants from federal agencies. These grants encompass many disciplines, from the life sciences and physical sciences to the social sciences and arts and humanities. 
Recent Successes

Some of UNL's major projects and centers include:

$>\$ 10.7$ million Center of Biomedical Research Excellence grant to establish the Nebraska Center for Virology in 2000 from the National Center for Research Resources, National Institutes of Health

> \$4.5 million grant for the Center for At-Risk Children's Services from the Department of Education in 2001

> \$9 million National Science Foundation EPSCOR infrastructure grant to support bioinformatics in 2001

$>\$ 10.5$ million Center of Biomedical Research Excellence grant to establish the Nebraska Redox Biology Center in 2002, from the National Center for Research Resources, National Institutes of Health

> \$6 million Plant Genomics Center funded by the National Science Foundation in 2002

> \$5.4 million grant from the National Science Foundation for a Materials Research Science and Engineering Center in 2002

$>\$ 1.8$ million from the National Science Foundation to study the Nebraska Sandhills ecosystem in 2003

$>$ W.M. Keck Center for Mesospin and Quantum Information Systems, established in 2003 with a $\$ 750,000$ grant from the W.M. Keck Foundation

> \$5 million from the National Institute of Child Health and Development in 2003 to develop strategies to enhance school readiness in children ages birth to age 5, in partnership with the University of Nebraska Medical Center, Lincoln Public Schools and the Lincoln Action Program

> In partnership with the DynPort Vaccine Company of Fredrick, Maryland, an \$11.4 million grant in 2003 from the National Institute of Allergy and Infectious Diseases for vaccine development.

$>\$ 9$ million infrastructure grant from the National Science Foundation EPSCoR in 2004, in part to support nutritional genomics studies of how complex chemicals in food influence growth and development in organisms

$>$ \$5 million Teacher Institute grant from the National Science Foundation in $\mathbf{2 0 0 4}$ for the Math in the Middle Institute

> \$750,000 from the National Endowment for Humanities in 2001 to establish the Great Plains Humanities Alliance.

It is worth noting that these large collaborative grants have not only been in the life and physical sciences, but include the environmental sciences, social sciences, education and the humanities. 


\section{Approaches}

Although initiatives supporting multidisciplinary collaborations, providing seed funding and infrastructure support for faculty, and grantsmanship seminars have been key in these successes, the most critical factor is faculty leadership. In all of these cases faculty conceived innovative ideas, and had the experience, desire and commitment to put together strong teams and prepare winning proposals. Incentives such as seed funding of research clusters and targeted retreats to bring together faculty from multiple disciplines also were important factors in building these successful collaborations.

Highlighted below are two such collaborations: the Nebraska Center for Virology, an established, thriving partnership; and the Water Resources Research Initiative, a budding initiative.

\section{Nebraska Center for Virology}

The Nebraska Center for Virology at UNL is led by Dr. Charles Wood, the 3M/Lehr University Professor. Dr. James Van Etten, University Professor in Plant Pathology at UNL and a National Academy of Sciences member, and Dr. Howard Gendelman, an endowed Professor at the University of Nebraska Medical Center, serve as co-Directors, and Dr. Clinton Jones, a Bessey professor in Veterinary and Biomedical Sciences at UNL serves as associate director. The Center links faculty from the three major biomedical research institutions in Nebraska: the University of Nebraska-Lincoln, the University of Nebraska Medical Center (UNMC), and Creighton University. UNL faculty who are involved represent three departments in the College of Arts and Sciences and the Agricultural Research Division of the Institute of Agriculture and Natural Resources: Biological Sciences, Plant Pathology, and Veterinary Biomedical Sciences. The center reports to the Vice Chancellor for Research. Senior research officers from UNL, UNMC, and Creighton serve on an internal oversight committee and the center has an external advisory committee of distinguished virologists from around the country. The Center sponsors regular seminars and an annual symposium featuring presentations from the faculty, nationallyrecognized guest speakers and the external advisory committee members. The center also has core facilities at both UNL and UNMC. The NCV has hired five new faculty lines with funding from the original grant and additional institutional support, plus four additional virologists, creating a critical mass of virology researchers in Nebraska. The NCV has leveraged these resources, recruiting established faculty with existing $\mathrm{NIH}$ funding and adding new $\mathrm{NIH}$ project funding and training grants. The Nebraska Center for Virology has served as a model in pursuing large grants and is a trendsetter in fostering collaboration across campuses. 
Water is a critical resource in Nebraska and nationally. Nebraska is the home of the Ogalalla aquifer, 65 percent of which lies beneath the state. Because of the significance of water to the state, UNL has made significant investments in this area, and more than 70 faculty from four colleges (Arts \& Sciences, Engineering, Agricultural and Natural Resources, and Law) have research interests related to water, including expertise in water quality and quantity, surface and groundwater hydrology, drought, and global climate change. Additional faculty are being recruited to further strengthen this critical mass in water research. The state also has made significant investments in state-of-the-art water quality instrumentation in the UNL Water Sciences Laboratory. To coalesce these resources around critical research topics, UNL launched a Water Resources Research Initiative in 2003, led by Dr. Kyle Hoagland, professor in the School of Natural Resources; Dr. Sheri Fritz, a professor in Geosciences; and Sandy Zelmer, professor of Law, working in concert with the Vice Chancellor for Research. The first steps in the Initiative were brown bag lunches and a faculty retreat to identify productive research areas, and sponsorship of the first Water Law, Policy and Science Conference in the spring of 2004. Faculty currently are pursuing several large funding opportunities as a result of these activities.

\section{Conclusions}

At UNL we have found that faculty effort and institutional commitment are important for creating a culture that is supportive of research and capable of moving the institution forward. In the above examples, faculty leadership is the key - in developing innovative ideas, providing expertise and serving as the driving force in successfully launching these initiatives.

To provide incentives for faculty to take on these large and difficult but highly rewarding projects, we are also strategically investing internal funding. New funds have been allocated to about 20 priority programs that are either strong or are of strategic importance to the state and can be strengthened with additional investments. Core instrumentation facilities are essential, and seed funding has also been critical in bringing faculty together and in enabling teams to generate preliminary data. In addition to regular faculty seed grants, we have initiated strategic planning grants of two types: $\$ 5,000$ to $\$ 10,000$ over two years to bring faculty together to plan and develop initiatives; and strategic cluster grants of $\$ 50,000$ to $\$ 100,000$ to develop inter-disciplinary collaborations aimed at large funding opportunities. These funds have been provided competitively with an expectation that teams aggressively leverage these funds with extramural funding. 